\section{Archibald Cochrane (1909-1988)}

$E$ 12 de enero de 1909 nació en Kirklands, Escocia, Archibald Cochrane ${ }^{1}$, quien al final de sus días iba a presenciar la gestación de lo que ha sido denominado, por algunos autores, un cambio de paradigma en la forma como se toman las decisiones en las profesiones de la salud. Cambio de paradigma por el cual Cochrane luchó durante su larga y accidentada vida y que se materializaría, finalmente, en lo que ha sido Ilamado Medicina Basada en Evidencias, definida como "el uso consciente, juicioso y explícito de la mejor evidencia al momento de tomar decisiones respecto al cuidado de nuestros pacientes individuales, integrando la experiencia clínica con la mejor evidencia externa disponible originada en la investigación sistemática". Para que un modelo de toma de decisiones de estas características tuviese éxito era imprescindible, pensaba Cochrane, que se contase con un sistema de acceso expedito a resúmenes sobre los resultados de la investigación clínica de la mejor calidad metodológica -es decir, de los ensayos clínicos randomizados- que estuviese a disposición de los tomadores de decisiones en todos los niveles del sistema de salud en que éstas ocurren. Desde el clínico hasta el planificador sanitario. Su forma de pensar está plasmada en la que fue su obra seminal: "Effectiveness and Efficiency: Random Reflections on H ealth Services", publicada en 1972 y reeditada en 1999 por la Royal Society of M edicine, en la cual sentó las bases de lo que hoy puede entenderse como la evaluación moderna de las tecnologías sanitarias y sus criterios de incorporación a sistemas de prestación de cuidados sanitarios, públicos o privados. Su sueño de toda una vida fue materializado, póstumamente, por la Colaboración Cochrane, fundada y organizada en torno a su memoria y cuyo propósito es "preparar, mantener y difundir revisiones siste-

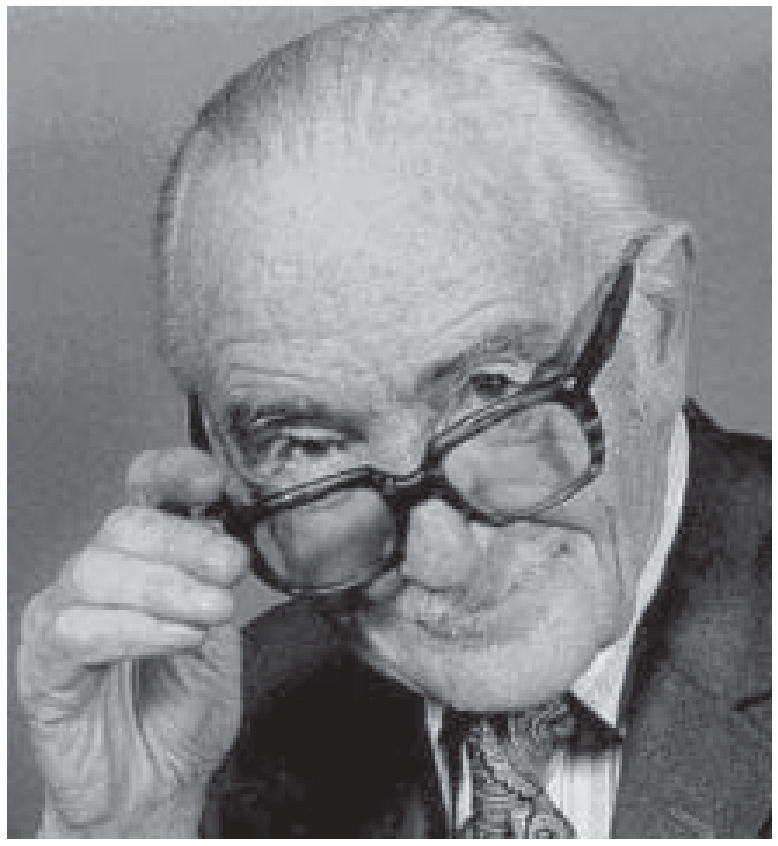

Foto reproducida con la autorización de The James Lind Library

máticas sobre los efectos de la atención sanitaria". Cualquier reseña sobre la vida de Archibald Cochrane sería, sin embargo, notoriamente incompleta, si se limitase a reseñar su trayectoria y legado académico. Aunque es importante señalar que se graduó como médico -con honoresen la Universidad de Cambridge, que fue galardonado como Doctor Honoris Causa de las Universidades de Rochester y York e invitado como profesor visitante a numerosas universidades, para posteriormente culminar su carrera clínica como Profesor de Neumotisiología en la Escuela Nacional de Medicina de Gales y Director de la Unidad de Epidemiología del Medical Research Council, tal vez los aspectos más atractivos de su biografía son aquellos que escapan a este recuento formal de sus logros. En 1931 interrumpió sus estudios médicos para radicarse en Berlín, donde acudió al Kaiser Wilhelm Institute para psicoanalizarse con uno de los más distinguidos discípulos de Sigmund Freud: Theodor Reik (18881969), a quien seguiría a Viena y La H aya, a medida que éste huía de la persecución nazi. En 1934, a su regreso al Reino Unido, retoma sus estudios 
médicos para suspenderlos, una vez más, al cabo de dos años. Esta vez para viajar como voluntario a la Guerra Civil Española, donde se enroló en las fuerzas republicanas como auxiliar médico en las Brigadas Internacionales. A su regreso se graduó, finalmente, dando inicio a su carrera profesional como médico en la ciudad de Londres. A poco andar, sin embargo, su naciente carrera se vio interrumpida por la segunda guerra mundial, al ser enrolado como capitán de la Armada Real Británica y, a poco andar, hecho prisionero en el frente de Creta el año 1941. Permaneció en su condición de prisionero de guerra hasta ser liberado en 1945, cuatro años después, luego de haber sido trasladado sucesivamente a campos de concentración en Grecia y Alemania. Estos años, en que actuó como médico en un frente de batalla y en que permaneció, por cuatro años, recluido con soldados de distintas nacionalidades, a menudo como médico único y sujeto a indecibles restricciones, lo marcaron profundamente y, según sus biógrafos, se encuentran en la raíz de su posición crítica respecto al conocimiento médico tradicional. En su libro "Effectiveness and Efficiency: Random Reflections on H ealth Services", reflexiona Cochrane de la siguiente manera: "recuerdo que en ese tiempo, al leer uno de los panfletos propagandísticos que se consideraba apropiados para oficiales médicos prisioneros de guerra, sobre "libertad clínica y democracia", los encontraba incomprensibles. Tenía suficiente libertad para elegir las terapias: mi problema era que no sabía cuál usar y cuándo hacerlo. Gustoso habría sacrificado mi libertad por un poco de conocimiento. Nunca había escuchado hablar de "ensayos clínicos randomizados", pero sabía que no había evidencia real de que aquello que ofrecíamos tuviese algún efecto sobre la tuberculosis y tenía el temor de haber acortado la vida de algunos de mis amigos con el uso de intervenciones innecesarias". Su desarrollo profesional, como clínico, epidemiólogo, académico e investigador, reflejó directamente su preocupación en esta materia. El cuestionamiento crítico sobre la eficacia y la eficiencia de las terapias utilizadas en medicina fue uno de los hilos conductores de su carrera. El interés no se limitó, sin embargo, a esta dimensión de la atención médica. Profundamente motivado por un interés de carácter social, tomó como propia la batalla por el acceso equitativo y oportuno a la atención de salud cuando ésta fue requerida y necesaria. Prueba de ello fue la pancarta con la que acudía a las concentraciones que en Inglaterra precedieron la creación del Servicio Nacional de Salud. En ella se leía el siguiente slogan: "todo tratamiento efectivo debe ser gratuito". Efectivo y sin barreras económicas de acceso, un anhelo que hoy es más vigente, tal vez, que en la época de Archibald Cochrane. Sería un error, sin embargo, pensar que el cuidado de salud al que se refería Cochrane era uno de carácter excesivamente medicalizado. Que las dimensiones del cuidado excedían largamente las fronteras de lo médico lo reconoce en uno de los trozos más conmovedores de su auto-biografía, en que relata un episodio que le ocurrió en sus años de prisionero de guerra: “... los alemanes arrojaron un prisionero de guerra soviético en mi guardia una noche. La guardia estaba repleta y lo coloqué en mi pieza pues se encontraba moribundo y no quería que sus gritos despertasen al resto. Lo examiné. Tenía grandes cavernas bilaterales y un notorio frote pleural. Pensé que este último era el causante del dolor y de los gritos. No disponía de morfina, sólo de aspirina, que no hizo efecto. M e sentí desesperado. Sabía muy poco ruso en ese entonces y no sabía de nadie más en la guardia que lo hablase. Finalmente, de modo instintivo, me senté en la cama y lo tomé en mis brazos. Murió pacíficamente". Archibald Cochrane murió, también pacíficamente, en 1988.

\section{Referencias}

1. Chalmers I. Archie Cochrane (1909-1988). In: The James Lind Library. Disponible en: http:// www.jameslindlibrary.org. 